Article

\title{
Audible Efforts: Gender and Battle Cries in Classic Arcade Fighting Games
}

\author{
Milena Droumeva \\ School of Communication, Simon Fraser University, Burnaby, BC V5A 1S6, Canada; E-Mail: mvdroume@sfu.ca
}

Submitted: 28 June 2019 | Accepted: 10 October 2019 | Published: 20 December 2019

\begin{abstract}
Video games are demanding work indeed. So demanding that our screen heroes and heroines are constantly making sounds of strife, struggle, or victory while conducting surrogate labor for us running, fighting, saving worlds. These sounds also represent the very real demanding labor of voice actors, whose burnout and vocal strain have recently come to the fore in terms of the games industries' labor standards (Cazden, 2017). But do heroes and she-roes sound the same? What are the demands-virtual, physical, and emotional-of maintaining sexist sonic tropes in popular media; demands that are required of the industry, the game program, and the player alike? Based on participatory observations of gameplay (i.e., the research team engaging with the material by playing the games we study), close reading of gendered sonic presence, and a historical content analysis of three iconic arcade fighting games, this article reports on a notable trend: As games selfpurportedly and in the eyes of the wider community improve the visual representation of female playable leads important aspects of the vocal representation of women has not only lagged behind but become more exaggeratedly gendered with higher-fidelity bigger-budget game productions. In essence, femininity continues to be a disempowering design pattern in ways far more nuanced than sexualization alone. This media ecology implicates not only the history of best practices for the games industry itself, but also the culture of professional voice acting, and the role of games as trendsetters for industry conventions of media representation. Listening to battle cries is discussed here as a politics of embodiment and a form of emotionally demanding game labor that simultaneously affects the flow and immersion of playing, and carries over toxic attitudes about femininity outside the game context.
\end{abstract}

\section{Keywords}

battle cry; games; gender; media; representation; sound; voice

\section{Issue}

This article is part of the issue "Video Games as Demanding Technologies" edited by Nicholas David Bowman (Texas Tech University, USA).

(C) 2019 by the author; licensee Cogitatio (Lisbon, Portugal). This article is licensed under a Creative Commons Attribution 4.0 International License (CC BY).

\section{Introduction}

Video games are demanding work indeed. So demanding that our screen heroes and heroines are constantly making sounds of strife, struggle, or victory while conducting surrogate labor for us running, fighting, saving worlds. These sounds also represent the very real demanding labor of voice actors, whose burnout and vocal strain have recently come to the fore in terms of the games industries' labor standards (Cazden, 2017). Battle cries as media artefacts involve technological demand, interactional demand, physical demand, and emotional demand: concepts defined by Bowman (2018) in articulating games as demanding technologies. One question that we can then ask is do male and female action leads sound the same? What are the demands-virtual, physical, and emotional-to maintaining sexist sonic tropes in popular media; demands that are required of the industry, the game program and the player alike? To say that mediated voice performance has always been gendered is well-documented, particularly in the area of film studies. Media writers such as Mary Ann Doane (1985), Kaja Silverman (1988), and Clarice Butkus (2010) have long brought attention to the gendered sonic positioning of the female voice in popular media in terms of vocal tone, accent, and role in the screen's diegesis. Historians of radio similarly offer accounts of the subordination of female sound (e.g., representing hysteria, nur- 
turing, or seduction) in relation to the male voice (invoking authority, confidence, authenticity), which has come to symbolize the technology of radio itself (Loviglio, 2007; Zakharine, 2013). Ann Carson (1985) and Mary Beard (2014) provide historical interpretations of the symbolic standing of women's voice in antiquity, as unbalanced, uncontrollable, and unpleasant-all qualities that justified the silencing of women in public communication, political life, and early media participation (Zakharine, 2013). In her study of the history of the operatic voice, Constance Clément (2000) further articulates stereotypical relationships between voice typology and narrative standing (e.g., tenor voice as hero, soprano as tragic love interest). However, attention to voice and sound is still sparse in cultural game studies: a significant gap considering the importance of sound in game design and its experiential presence during gameplay (Droumeva, 2018). In this project, I take up the battle cry as the core indexicality of voice in games, akin to vocal presence in cinema, and apply a critical media studies lens to the sonic representation of women. As Sterne (2003) argues, mediated voice is situated between authenticity and the politics of technology, and manifests through sets of audile techniques: standards and conventions, which become discursive grammar for media production and consumption. The historicity of vocal presence in games-the battle cry-then constitutes a unique perspective from which to examine the politics of embodiment.

The battle cry, it can be argued, is the quintessential vocal presence of a playable character; a temporally persistent audio-visual aspect of the demanding labor of gameplay and a chief aspect of a synchronous flow state (Weber, Tamborini, Westcott-Baker, \& Kantor, 2009). It is also a sound effect that embodies gendered, racialized, and class connotations by virtue of sonifying a constructed body (the avatar). It is important to note that discussions around gender representation and design in games have historically focused on differences between cis-gendered male and female avatars. While exciting work focusing on non-binary and queer characters, monsters, and hybrids is now emerging (Ruberg, 2019), this article limits its analysis to binary gender representation. There are two reasons for this: 1) Sound is underexplored in game studies and our mixed methods study has a limited scope that aims to address a still-entrenched gender dichotomy; and 2) what we demonstrate with this work is that there is yet further exploration to be done in understanding the nuanced and multi-faceted ways in which game characters are gendered, which itself is foundational to representation of non-binary, queer, and/or non-human avatars. By focusing on this specific vocalization this project offers a model for doing media analysis of sonic representation akin to studies done in visual representation of gender, race, and sexuality in screen-based media. Specifically, analyzing the battle cry as a demanding artifact of technology at the same time as exploring its implications for the player means that we can refresh the conversation about gendered media tropes and their role in facilitating or burdening the "player-program dialogue" (Bowman, 2018). To that end, this article reports on a notable trend: As games self-purportedly and in the eyes of the wider community improve the visual representation of female playable leads, important aspects of the vocal representation of women has not only lagged behind but become more exaggeratedly gendered with higher-fidelity bigger-budget game productions. In essence, femininity continues to be a disempowering design strategy in ways far more nuanced than visual representation alone. Thinking about gendered vocal tropes in games as a form of emotional and social labor brings into focus the reality that resisting and shifting entrenched (but harmful) mediatized conventions requires equally demanding cultural labor. Since video game design, including audio-visual synchresis, produces virtual as well as actual affective states (Banks \& Bowman, 2016), this work is also a feminist take on voice and gender as aspects of gaming necessarily tied to (but often lacking) in research on emotion, affect, and flow states in gameplay.

\section{The Battle Cry Study}

This project traces both qualitatively and quantitatively iterations of the battle cry across three iconic series in the genre of fighting arcade games: Mortal Kombat (MK), Street Fighter (SF) and Soul Calibur (SC). The intention is to map how the demands for greater and better gender representation in games have unfolded over time in terms of industry conventions, technological advances, and purposeful design of gender differences. If we consider battle cries as 'audible efforts' emitted by avatars that make interactional and emotional demands on the player, how might this experience be gendered? This battle cry study cuts across three layers of analysis: 1) Historical content analysis of female vs. male avatar vocalizations in terms of percentage of battle cries in fight sequences; 2 ) close reading of the gendered staging of battle cries using spectrograms and participatory play-observations; and 3) an interpretive analysis of battle cries as demanding technological artefacts within a player-avatar sociality matrix (Banks \& Bowman, 2016). Mobilizing the concept of 'demand' literally, figuratively, and virtually towards the production and experience of battle cries opens space for a novel critique of persistent sexist tropes in games. By locating battle cries within the player-avatar matrix of sociality we can better understand the "mechanisms underlying affective and cognitive states during gameplay" (Banks \& Bowman, 2016, p. 211). Ultimately, this project hopes to challenge the games industry to introduce new cultural demands of the player-ones that are compatible with a complex and equitable view of gender and identity in popular media.

Classic arcade fighting games were selected for this analysis in their capacity as influential trendsetters for subsequent game genre design with regard to not only representation, but also aesthetics and mechanics. The 
impetus for this work came in part through personal experiences with arcade fighting games, and in part through conversations in the wider gaming community about 'playing as a female character': an activity that is still 'other' enough to the normativity of playing-asmale to warrant continued discussion. The first central observation in this study, and one that aligns with Carson (1985) and Beard's (2014) accounts of women's historic silencing is that women are just so quiet in early versions of arcade fighting games. That is, they emit battle cries far less frequently than their male counterparts. Curious to test out whether that was indeed the case as a historical and genre trend we designed a mixed-methodology study focusing on battle cries that included gameplay, observations and field notes, content analysis (tallying distribution of male to female battle cries in a given fighting sequence), and close reading of narrative-sonic elements. The first stage of the study involved distilling several sonic tropes in terms of tonal character, vocal parameters and presence, using film media theory as a guide to formulating voice typologies.

\subsection{Gender Coding and Sonic Tropes}

In order to distill female battle cry typologies we looked across 286 fighting sequences with 30 unique female arcade fighting characters across the three abovementioned franchises, with footage ranging from 1993 to 2015. Naturally, in earlier titles audible differentiation between gendered opponents involves simple spectrum shaping to synthesize lower or higher frequency tonal bursts, and vocalizations are generally sparse. The emphasis in those early soundtracks is on upbeat music, noise burst 'punches' and intermittent voice-off combat phrases. As console technology improved over time in terms of fidelity and compression (as well as hard drive space allocated to sound), game design began importing pre-existing vocal stereotypes from cinema and advertising, which unfortunately further entrenches cultural constructs of femininity (Clément, 2000; Doane, 1985; Silverman, 1988). Common theatrical, broadcasting, and cinematic tropes such as creaking, sultriness, hysteria, naiveté, and 'female masculinity' voice (Loviglio, 2007) persist in game soundscapes through the craft of vocal acting. Based on participatory play-observations which involved the research team playing games (separately and together), research memo writing based on gameplay, and group discussion of gameplay captures, our team developed three consistent female vocal typologies in the arcade and early role-playing games genres. While these are discussed elsewhere in more detail (Droumeva, Evans, Fertado, \& Bangert, 2017), briefly, they include the 'warrior woman' voice, the seductress, and the 'buttkicking doll' voice. The warrior woman (e.g., Sonya Blade) is a confident female voice of medium-high register with clear timbre, coded as middle-class and white, often featuring British or (non-regional) American accent. The warrior uses low tones, and is only breathy to accentu- ate the importance in what she is trying to communicate. In the same way as lowering the vocal register afforded female radio personalities airtime and respect in more 'serious' news domains (Loviglio, 2007), the warrior woman's voice in popular media marks the emergence of the 'strong female lead' (Kennedy, 2003) alongside traditionally male superheroes. Her clear accent and enunciation marks her higher status compared to other often regionally-accented characters (Ensslin, 2011). The butt-kicking doll (e.g., Sakura) embodies a notion of sexualized innocence; vocally she is overly apologetic, playful and giggly, and her voice is often artificially pitched up, light, breathy, and squealy. This vocal trope, particularly in Japanese-originating game titles, is part of a wider cultural context of female infantilization in anime and the deployment of squeal and brethiness as vestiges of pornography (Butkus, 2010). Yet, in western pop media we see similar trends in the teenage pop voice (James, 2016), and the ideal of the virginal woman as innocent, childish, or angelic (Silverman, 1988). The seductress (e.g., Mileena) is a witch trope: Her vocal traits of low drawl, creaking, and growling possess elements of overt inviting sexuality intrinsically linked to a kind of otherworldly quality about the witch-deep-seated evil, connections to magic and the arcane, and/or physical hybridity or deformities. The witch is possibly the oldest formulation of agential female character, dating back to antiquity (Carson, 1985), and the more modern history of Western opera. In her work on gender representation, operatic training and early popular entertainment, Constance Clément (2000) positions the mezzosoprano-a lower register typically raspy female singing voice-as consistently narratively aligned with evil, sexuality, spirituality, and being outcast from 'normal' society. Sultry breathiness was also established as a film standard in early expressive cinema with Marylin Munroe's boudoir vocal performances marking her as always already sexually charged. Finally, the witch in games is powerful and taunting, much as the witch in opera is one of the only women with agency over their life, openly flaunting their power and freedom (Clément, 2000). For the content analysis portion of this research, one example of each vocal typology was selected for analysis, per title, and followed over time.

\subsection{Battle Cry Content Analysis}

The battle cry content analysis spans historically over several iterations of each game from 1993 to 2015, including: MK II, IV, 9, and X; SF II, IV and V; SC II, IV and V. We traced major franchise characters Mileena, Kitana, and Sonya Blade (+ Jury) from MK; Chun Li, Cammy, and Sakura from SF; and Taki/Hilde, Ivy, and Xianghua/Leixia from SC. A total of 166 fighting sequences have been played and captured representing 15-20 fights for each character of interest. This includes 10 games and 69 characters (12 female playing against a total of 57 male opponents). To be clear, this small-scale case study lacks 
the scope of data collection to adequately address the politics of technology as part of the apparatus of representation, nor the historical granularity to excavate indexical changes in mediated embodiment through sound (Sterne, 2003). Instead, this is a theory-informed model for doing interpretive content analysis that takes up Doane's (1985) notion of the 'fantasmic' female voice in order to attempt to decode the technological, discursive, and political aspects (Sterne, 2003) of game characters' vocal embodiment. To that end, any claims made regarding technological evolution of battle cries as sound technology artifacts are interpretive and illustrative, intended to engage the ethos of game platform advancement as part of the hegemony of gender representation. A note on game iterations selection: Since we wanted to focus on 1) direct title iterations rather than special editions, and 2) the contract between older and newer games, the selected titles are not equally spaced chronologically (e.g., MK IV was released in 1997, while MK 9 in 2008). With these limitations in mind, this proof-ofconcept case study of battle cries aims to shed light on a certain evolution of female representation in games manifest in sonic terms. For consistency's sake we focused on the console version of the games; older titles had to be played on emulators while newer titles were played in-house on a PlayStation 3 and 4 respectively. In some cases, however, if was difficult to obtain and play certain titles and so we turned to and captured YouTube videos of corresponding fights. It is important to note that many published YouTube videos of arcade fighting gameplay feature extra-hard modes or 'best of' fatalities, showcasing the gaming prowess of the author. We wanted to instead develop - both in our own gameplay, and in YouTube capturing conditions-a constructed 'average play' scenario for each fight. An average fight would involve the classic version of each character and a fighting choreography where both characters deal similar amounts of damage at a medium difficulty setting. Further to that, in order to avoid deriving conclusions from single fights, each character's battle cry count is an average of 5 random fights with different male opponents (to account for character specificity) where some fights were won and some lost. The battle cry coding schema included counting the number of combat verbalizations such as grunts, pants, sighs, straining noises, and any reaction sounds when getting hit, excluding the sounds of feet stomping on the ground or the impact of punches and kicks landing on the bodies of opponents. We looked at cut-scene phrases (e.g., at the beginning or end of a fight) separately but counted voice-off remarks during fights as gendered vocalizations and part of the coding schema. Battle cries were coded for both female and male characters, by two separate coders who cross-checked work to ensure consistent application of the coding rules. Coding was performed using Screenflow for video playback and a simple log sheet.

As a global finding our quantitative analysis shows that female battle cries have increased over $300 \%$ across all three titles between the mid-1990s and the mid2000s (see the MK chart in Figure 1 for average numbers of battle cry instances in a fight sequence). This can be attributed to the industry's evolving standards for more authenticity through higher quality graphics and sound, and the shift to voice acting instead of sound synthesis coupled with higher memory allowance for audio on console games. A $300 \%$ increase of average in-fight vocalizations are representative of both an increased demand on the game system and an increased demand for the laboring avatars (not to mention the labor of vocal actors sonifying these game events). So how is this demanding sonic presence gendered?

A look at the quantitative distribution of female-tomale battle cries historically reveals some interesting patterns that converge and diverge across titles (see Figure 1). Overall, the female warrior character is most vocally restrained producing $42-48 \%$ of battle cries on average. Yet while Hilde's (SC) count remains steady over time at $48-49 \%$, Chun Li's vocalization feature a massive increase from earlier iterations of SF at 37\%, going up to $53 \%$ of battle cries in the last iteration of SF. Sonya Blade displays a more modest but similar trend growing from $42 \%$ to $53 \%$ of in-fight vocalizations between MK IV and MKX. In SF, the butt-kicking doll Sakura actually sees a decrease in her vocalizations over time going from an average of $52 \%$ down to $47 \%$, while SC's corresponding characters Xiangua and Leixia see a modest increase from $52 \%$ to $54 \%$ on average. Interestingly, in our gameplay experience the butt-kicking doll seemed like the most vocal trope, yet that is not necessarily reflected in the numbers. Instead it is the seductress that produces the most vocalizations historically, and sees a gradual increase over time in all three franchises, with Mileena (MK) being the most vocal of this sonic typology at an average of $56 \%$ of in-fight vocalizations in MK X. As made clear by the confidence intervals presented for each character's battle cry count in Figure 1, there were significant fluctuations depending on the fight situation, and these fluctuations are not historical (i.e., more recent titles fluctuate as well). At this stage of research they are likely due to the small sample of five to six fights for each character, however, it is important to note large fluctuations can naturally occur owing to randomized sound sampling in the game sound engine, player skill, difficulty setting, etc. During our participatory play-observations it was not uncommon to hear anywhere from $25 \%$ to $75 \%$ of female battle cry vocalizations in individual fights and, observationally speaking, the most vocally demanding trope was the butt-kicking doll with elongated, breathy phrases and cries, resulting in a more dominant sound profile overall compared with her various male opponents. Save for the largest outliers in Figure 1, this finding is supported by the confidence intervals presented; still, the range sizes call for further study in terms of content analysis using a larger sample of fight sequences and character pairs. Readers are invited to visit and interact with the study at http://osf.io/e4qrp. The open-source project folder con- 


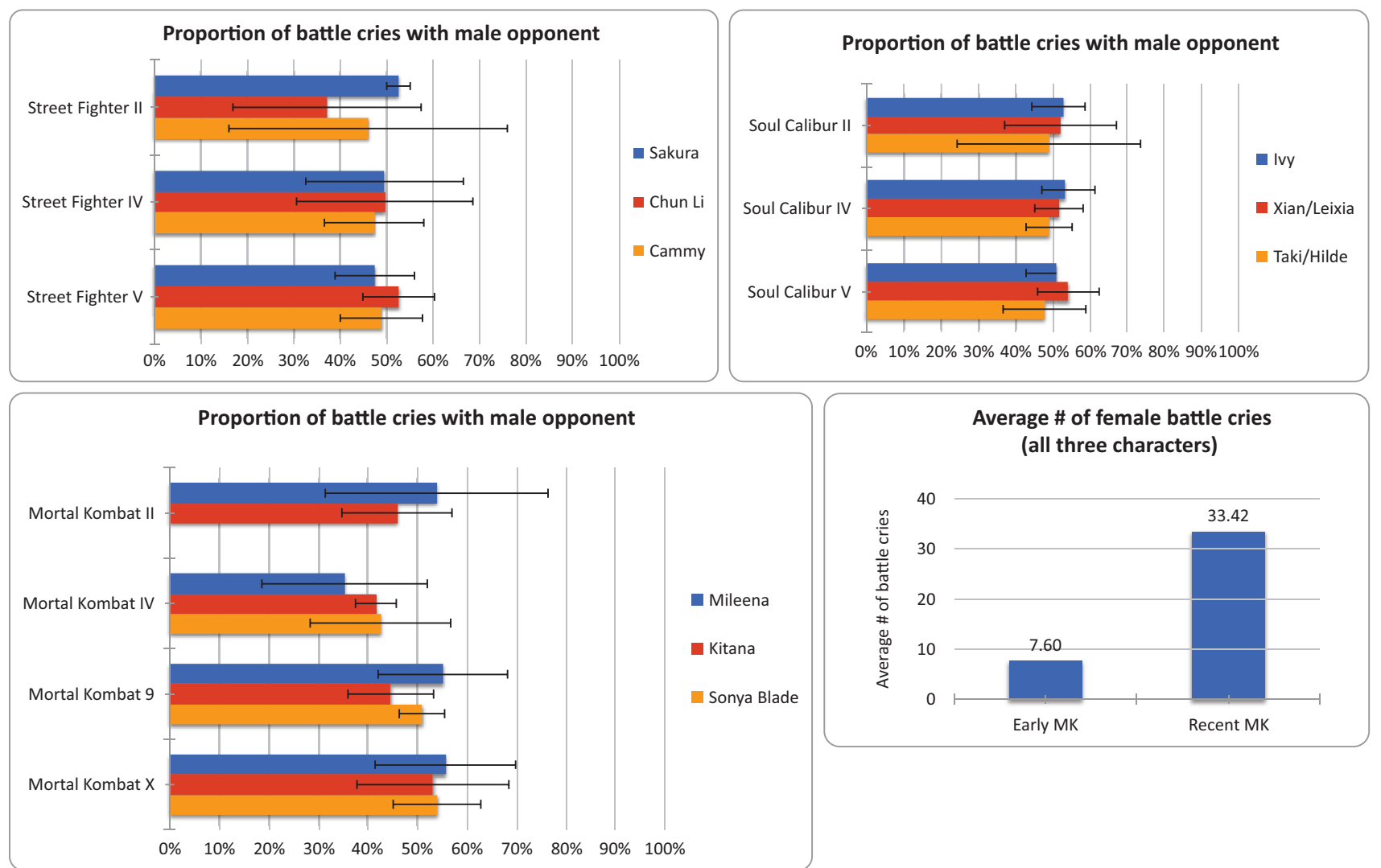

Figure 1. Charts comparing major franchise characters in terms of their average percentage of battle cries in fights with a male opponent. Notes: From top, clockwise-SF, SC, MK, and MK comparison of late 1990s vs. late 2000s actual instances of female battle cries.

tains the dataset in the form of spreadsheets with content analysis counts per title, along with a references document to YouTube videos used for the content analysis, and a video selection of our own gameplay captures.

\subsection{Sonic Presence and Audible Effort}

In our participatory observations, or close readings (Bizzocchi \& Tanenbaum, 2011) of arcade fighting gameplay, we note a clear shift between early (1990s) and later (mid-2000s and up) game titles in terms of gendered sonic differentiation for game characters. Sounds made by female characters are very similar if not identical to the male characters in early versions of MK. By MK IV (1997) the sounds emitted by characters in 'kombat' are different for men and women. One notable difference is that women grunt, sigh, and moan while male characters often speak threatening words: e.g., Scorpion will growl "Get over here!" throughout the fight. MK vs DC Universe (2008) features, like MK IV, more explicit sexualization of the characters visually and even further gendering vocally. The defensive noises from women are over-the-top wails; in contrast, even when male characters emit a vocalization when hit, they are soft, short grunts. Female characters make less noise in general in this title, with Kitana making up $46 \%$ of total fight vocalizations and Sonya Blade 39\% respectively. With MK X
(2015) we see a turn to a more 'authentic' realism of the voice performances where battle cries are less exaggerated, and the timbral qualities of each voice matches more realistically the body type, age, and appearance of the female character. In SF we observe the same trend, in that both men and women are making defensive and offensive sounds; however, when a female character is injured the sound is generally weak and anguished, whereas males tend to make a big "Ooof!" type noise that indicates injury but not necessarily weakness.

On the surface, historical progression disproves the original observation that female avatars are 'silenced' in any political way. If anything, with time they take up more space in the sonic ecology of an average fight. However, a closer read of their sonic presence reveals an interesting trend: Women appear more vocal because they emit more vocal reactions to being hit; most male characters simply absorb the hit and do not vocalize at all; we just see their life stats go down. Female avatars yelp, cry, and shout in pain far more than their male counterparts, even when the point damage is minimal. In other words, even though there isn't (or shouldn't be) any algorithmic disparity between male and female avatar stats, women overwhelmingly vocalize pain and suffering more than their male counterparts, as if they are physically weaker, as if they struggle and feel more pain, and the fight is more demanding for them as the 
player's proxy. Looking beyond the surface, female characters do often have different/lesser life, attack, and defense stats even if that information is not very clear in the game or is complicated in console versions by character evolution and gear. As fans and gamers have long observed, female characters are gendered in terms of their very design and mechanics: posture that embodies their narrative typology (e.g., Juri contorting as a witch, or Leixia buckling at the knees as a teen girl warrior); these characters often feature suggestive, sexualized, or otherwise feminized combo actions-e.g., Sonya Blade's 'kiss' fatality, Ivy's dominatrix whip combo, or Sindel's 'migraine' scream. In developer circles the strength of characters has been discussed as a matter of authenticity: One of the designers of SF's iconic Chun Li for instance wanted to make her life bar shorter to reflect women's weaker nature, but was convinced otherwise (Lee, 2014). Similarly, official fan rankings of MK characters (Duran, 2018) in terms of strength place Sonya Blade-the classic female warrior-in 27th place out of 30; Mileena at 21/30; and only one woman places in the top 10Cassie Cage-a new character in MK X (2015), arguably a more 'modern' equity-aware design. Of course players have a variety of reasons for choosing to play (or not) female characters: Enjoyment, challenge, transgression, fantasy, arousal, role-play. The fact remains, however, that games continue to bake disempowering gender stereotypes right into the very appearance, combat style, and sonic presence of fighting heroines. The experience of playing as a female character is summarized below in a notable excerpt from a research memo from the project:

There is absolutely no power fantasy as a woman in Soul Calibur. In Mortal Kombat, I feel like I get into it sometimes; having Sonya Blade kick ass for me is exciting to see in a way. But [in Soul Calibur] the seductress and warrior woman are both making these helpless whimpering sounds and even their attack sounds are breathy and lackluster. (Evans, 2017)

These nuances led us to engage in a closer reading of the processes of gendered sonic embodiment in arcade games, including the congruence between characters' infight and voice-off vocalizations, and the qualitative aspects of their battle cries by breaking them down into offensive versus defensive sounds.

\subsection{Embodiment and Voice}

Battle cries in games are possibly one of the most visceral aspects of the embodiment of avatars within the player-program dialogue; with audio-visually advancement in later iterations characters also emit more voiceoff phrases during fight rounds: short remarks, taunts, and reactions that typify their particular personality. Voice-off remarks would fall into the wider trope of cinematic 'disembodied voice' whose history carries deeply embedded gendered practices of montage and representation. In her classic essay on the disembodied female voice, Mary Ann Doane (1985) explains that in film the 'fantasmic' female voice-over is marked as subordinate to the normativity of the authoritative male voice, and relegated to traditionally feminized functions representing emotional and subjective elements, interior monologue, and flashbacks. This categorization aligns well with the voice-off phrases that female characters 'speak' during fight sequences and their voice-over in cut scenes. These phrases are sometimes explicitly sexualized, hysterical, or naïve: again replicating the typologies of female voices in popular media (Clément, 2000; Silverman, 1988). For instance, while warrior women definitely battle cry in firm, mid-range confident tones, they are also heard uttering breathy lines such as: "I'm just doing my duty! Please don't take it personally..." (Chun Li), and "Shut up! Go away! Leave me alone!" (Cammy). The flippant dialogue and frequent use of helpless whimpers-particularly in the vocal profile of the sexy butt-kicking doll-only serve to undermine the fighting status of these women, despite what the backstory and character development might suggest. For instance, Xianghua's markedly infantilized battle cries reminiscent of Link's "Teyyyyahh!" are offset by her visual sexualization and accentuated further in the vocal presence of her daughter Leixia in SC V (2012) who constantly utters "Sorry!" and "Forgive me" while battling an opponent. Generally, in comparison with the gamut of male character voices featured in typical arcade fighting games, female avatars sound distinctly close-miked, breathy, with a lot of exhalation at the end of phrases (known in voice over work as 'pre life' and 'post life'), evoking urgency, self-doubt, and emotional affect. In this sense, while battle cries technically serve to sonify a fighter's prowess and exertion, in the case of female fighting avatars battle cries and voice-offs actually create incongruence with the characters' status owing to their gendered design. In order to do a closer reading of the gendered characteristics of battle cries, we used Adobe Audition to visualize the audio waveforms and spectrogram of a few select fights ranging from older to more recent titles (Figure 2); this was done as proof of concept and an attempt to nuance and complicate the content analysis portion of the research.

What we found is that incongruence of vocal presence between male and female characters extends to another dimension of battle cries: their tonal character and their narrative coding as offensive vs. defensive vocalizations. In a close reading of in-fight sounded elements across $\mathrm{MK}, \mathrm{SF}$, and SC, there seems to be almost no difference between when women take damage and when they're dealing damage to their opponent. In other words, even when sonic elements are almost equal, women simply sound most of the time as if they are being hit, while men make very few defensive cries, instead emitting offensive grunts and roars. Consider two micromoments from SF IV and SC IV respectively (Figure 2): 
(a)

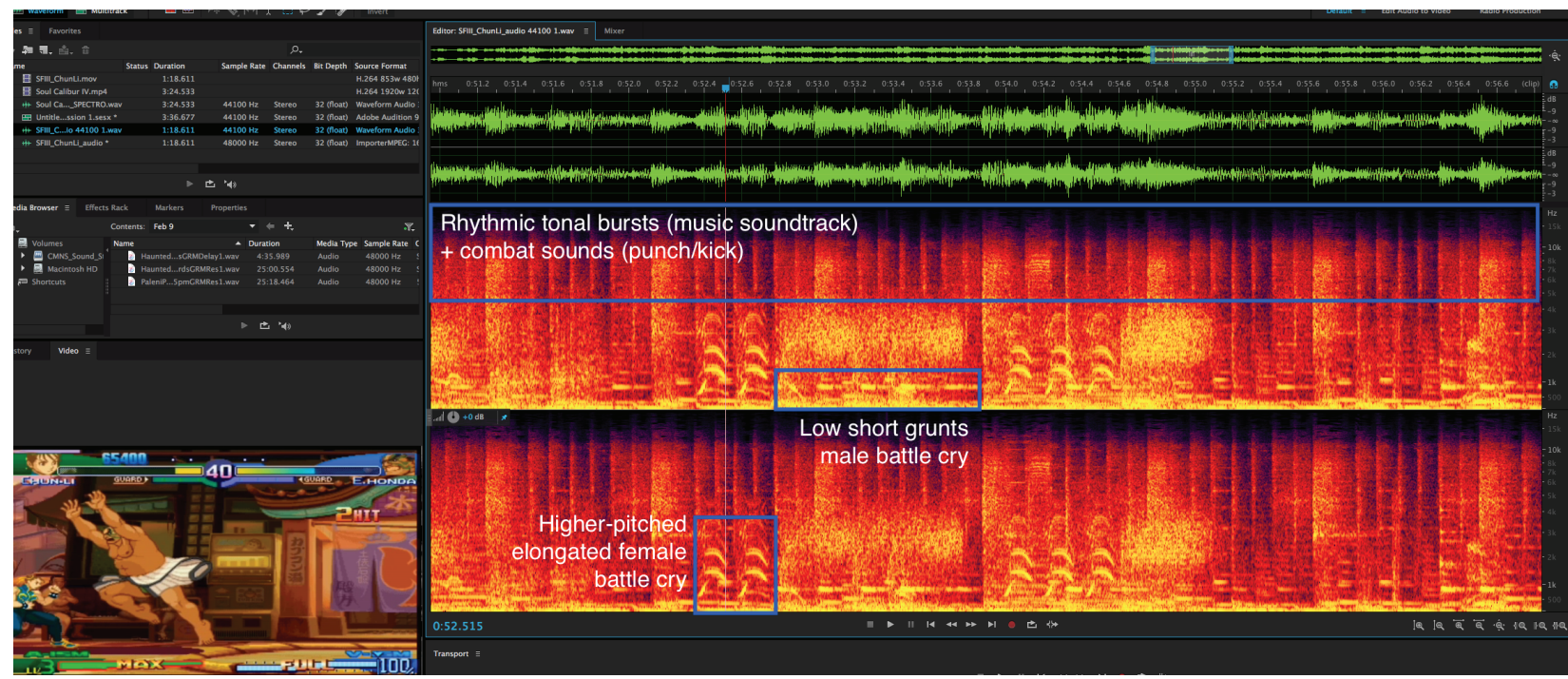

(b)

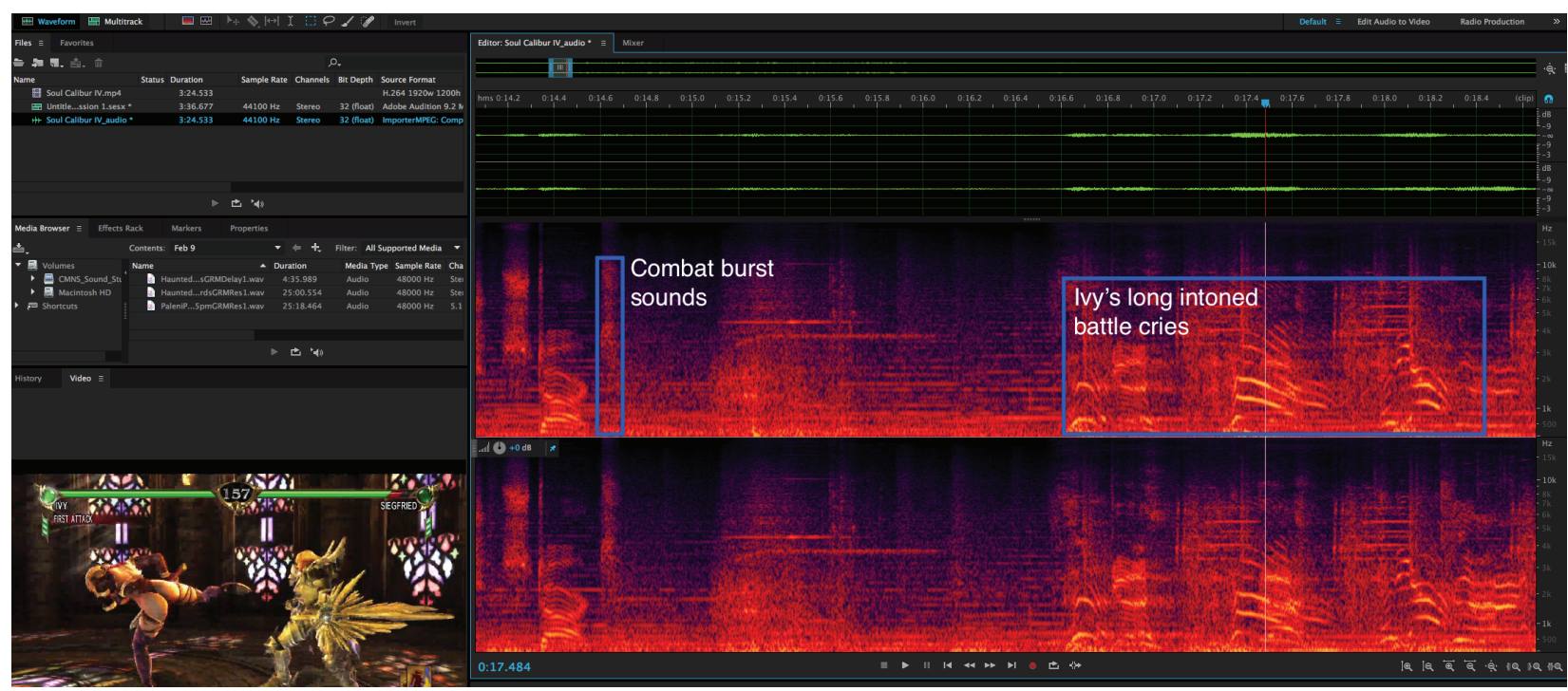

Figure 2. (a) Spectrogram of Chun Li fight section (SF IV); (b) Spectrogram of Ivy fight section (SC IV).

Compared to the short noise bursts of E. Honda's battle cries, Chun Li (a warrior vocal type) intones much longer battle cries descending in pitch, regardless of whether she is attacking, defending, or being hit. Even visually, as we can see in both combat screenshots, female vocalizations take on larger envelopes in the overall game soundscape: They demand more time and attention within the ecology of the gaming experience. This was an important finding as our coding schema of battle vocalizations didn't consider duration-just frequency of occurrence. Looking at the spectrograms provides grounds for future analysis from a temporal standpoint; in addition, it is significant to see almost no intoning in male grunts whereas women's battle cries are pronounced and contain almost musical harmonics.

The tonal character of these pitched battle cries is, historically, an invitation to a 'male gaze and ear' (Silverman, 1988) as a deliberate design choice that has persisted across media franchises. Oftentimes female vocalizations in games sound almost pornographic. How can they not-in Western hetero-patriarchal media culture sex is always potentially violent and violence is frequently sexualized (Corbett \& Kapsalis, 1996; Creed, 1993); furthermore the 'aural sexuality' of the recorded female voice is enmeshed with the history of sound recording itself (Butkus, 2010). This is particularly clear in the SC spectrogram in terms of Ivy's (a seductress) long breathy guttural battle cries which are even longer and more nuanced in terms of tone and harmonics than Chun Li's (Figure 2). Of course the two games are different stylistically, however, one reason for this development is the increased audio-visual resolution and voice work sophistication in the more recent game title: Affirming once again the finding that women are heard more now than before, however, in stereotypically sexualized and/or disempowering ways that explicitly mark their feminization. While we can trace some of the origins of these exaggerated breathy feminine sounds to a genre cousin-anime-this trope also builds on the 'scream queen' idea in film where the height of the action- 
whether horrific or pornographic-is punctuated by female screams (Bonenfant, 2014).

The effects of this kind of biased characterization can be farther-reaching than one might expect (BehmMorawitz \& Mastro, 2009). The way players talk about characters amongst themselves-on forums such as Steam or Reddit-speaks to an internalization of biased vocal representations of gender. A brief scan through the adjectives used by players to describe different gendered characters and their voices (both in positive and negative terms) helps illustrate this fact. For instance, tropes emergent from a Reddit thread (2016) discussing SF V character voices stages their traditionally negative qualities (shrill, weak, or irritating, etc.) in terms of sexuality or as comic relief ("sounds like a chain-smoker" or "nails on a chalkboard"). The connotations of strength, dignity, and guileless intelligence are reserved (in the players' perception) for male-voiced characters. Diminutives, overtly feminized terms, and condescending phrases appear much more frequently when discussing female character voices. Examples of adjectives and descriptors include the male boss voices being referred to as "natural" and "fun," and the female-voiced characters being referred to as "chick," "gal," "sweet," "baby," or alternatively "pitchy" (Reddit, 2015). Interestingly, these sentiments extend to discussions of the actors behind the character voices. Laura Bailey and Nolan North are both very well-known voice actors; however, in online discussions she "yelps" (in the negative), or is "comforting" (in the positive); while he is described as "incredible" and "a badass." (Reddit, 2015). The power of the disembodied voice is thus located in the symbolism of the voice itself. As Butkus (2010) notes, the media ventriloquism that is facilitated by the very fact of recording technology serves to mediate, and even legitimize, our experiencing these vocal sounds as e.g., irritating, pleasant, abject, arousing, weak, strong, etc. After all, they are simply 'sound effects' - abstracted instances of pure vocal symbolism delivered as rapid-fire feedback to the player. But are they? A body of literature on the emotive and psy- chological aspects of gaming suggests that para-ludic elements of game design such as sound, aesthetics, narrative, and representation (among others) are highly constitutive of the affective and emotional states of gameplay within the player-program dialogue (Bowman, 2018).

\section{Battle Cries and Player-Avatar Sociality}

According to Bowman (2018) technological demands propel game design to improve the rich and pleasurable experience for the player; interactivity-as-demand addresses the dialogical nature of player input and game program as a process that requires active cognitive, psychological, and cognitive states; physical demand touches on the embodied nature of this interactivity; and social and emotional demands refer to the inherent 'affective' experience of interacting with other agents such as avatars, environments, and players. Social and emotional demands are also inextricably connected to levels of immersion, engagement, and investment in the game world. Figure 3 offers an illustrative weighting of these demands in relation to battle cries in arcade games specifically. Given the process of recording and encoding sound effects banks in the game's platform, their technical demand is low: They are called up when needed, looped, randomized, and repeated; their interactional demand is, I propose, at least medium due to the active cognitive states of performing battle moves; these same battle moves entail even higher physical demands from the player. In terms of social and emotional demands I suggest battle cries elicit medium to high demand due to the arousal states that come from instant sonic feedback in quick-movement gameplay. The auditory voyeuristic pleasures of hearing sounds of pain, struggle, or victoryespecially when these sounds are feminized, potentially sexualized, and within direct control of the player-can also be seen as forms of affective labor or demand. To be clear, this figure is an illustration of a hypothetical average player scenario; a different setting, context, player, or interpretation might yield slightly different ratings.

\section{Battle cries in arcade fighting games in terms of demand on the player and the system}

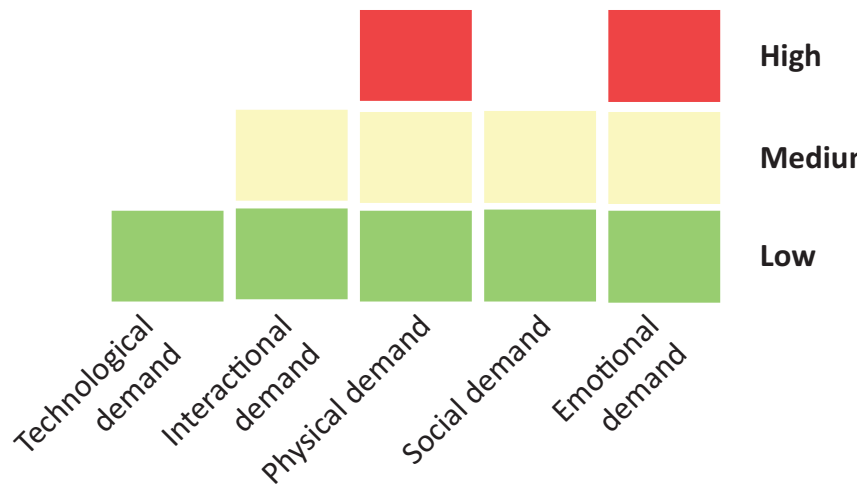

Figure 3. An illustrative breakdown of battle cries in arcade fighting games as demanding technologies. 
As Bowman (2018, p. 10) notes, the "player-program dialogue" has an intuitive emotive dimension to it in that the player feels rather than thinks through controller actions. Social demands in games naturally boost arousal and while sociality is largely understood as gamers' experiences with other social actors (gamers) in virtual spaces, the player-avatar relationship is an important form of sociality (Banks, 2015). In arcade fighting games the avatar is both iconic/independent in their own right, and highly controllable by the player: A combination that mimics mediated puppetry with the avatar's battle cries, yelps, and grunts rewarding the player for gaming mastery. In order to focus on the social and affective dimensions of gendered battle cries, I offer another interpretive breakdown of arcade games in terms of their playeravatar experience matrix, using Banks and Bowman's (2016) proposed PAX scale (Table 1). Once again, this table is not meant to suggest that there is a fixed configuration of PAR/PAX, rather, it suggests an illustrative case study of battle cries as a specific interactional element that significantly impacts the ludic experience of arcade fighting games. The proposed scale blends several aspects of gameplay into an evaluative rating of investment, immersion and engagement in the game world. Anthropomorphic autonomy is arguably high in arcade fighting games: Since the narrative is not first-person based, a close identification between player and avatar isn't specifically encouraged or facilitated. Avatars have a symbolic life outside the game as part of the franchise and popular culture in general; they are not highly customizable and so in terms of the PAX scale, emotional investment in the player-avatar relationship would be minimal (Banks \& Bowman, 2016). In terms of battle cries, arcade avatars are both seemingly independent, via randomization of feedback from battle cry audio banks, and at the same time persistent as ludic and aesthetic elements that are looped and repeatable. Even quantitatively, avatar vocalizations could take up to $85 \%$ of the battle's soundscape, so their affective power defines much of the player's experience during a fight sequence. In terms of suspension of disbelief, battle vocalizations can be characterized as hyper-real for both women and men, thus eliciting lower immersion on the PAX scale. Yet, the sense of player control (and thus, engagement and immediacy) are high owing to the feedback loop of controller-triggered avatar movements and avatar vocalizations as auditory rewards for the player.

Building on the PAX scale as a "model for examining mechanisms underlying affective and cognitive states during gameplay" (Banks \& Bowman, 2016, p. 221), let's return to the idea of battle cries as gendered audible efforts and as mediated artifacts that structure identification between player and avatar. I frame this speculative discussion around the interplay of avatar identification and affective demands specifically. According to Banks (2013) there are four stable player-avatar relationships that determine much of the player's experience of emotional investment, immersion, and engagement during gameplay: Avatar as Tool; Avatar as Symbiote; and Avatar as Other. These states of avatar identification determine the levels of sociality that the player experiences (Bowman, 2018, p. 15) and it is important to note that affective demands are experienced as real even when virtual, i.e., happening inside the gameworld. The feedback system of battle cries as a sonification of avatar bodies thus allows us a unique approach to probe avatar identification as a form of demanding affective labor for players of any gender.

First, the voice is not neutral but a highly emotive form of feedback central to the player's very sense of self as they try on and occupy different avatar identities (Banks \& Bowman, 2016). While the battle cry is an algorithmic recorded sound effect for the game, it is also the primary form of embodiment for the avatar, and to quote Christine Ehrick (2015), there is no such thing as a disembodied voice, because voice always hearkens to a body; the voice is a person, and the mediatized voice is historically indexical to technological politics (Sterne, 2003). In a highly interactive entertainment genre such as games-a media text filled with semiotic shortcutsvoice is a direct signifier for gender (not to mention race, class, etc.). Voice is the avatar itself and the avatar is a puppet directed by the player. The soundtrack can be viewed as a ventriloquist (Altman, 1980) that serves to disguise the cultural logic of game design from the player, instead immersing them in a fast-paced feedback loop of action and reward. Since voice is gendered, identifying with an avatar, even at a low level, is a kind of gender play. To that end film and media studies tell us that the mediated female voice can no more escape the connotations

Table 1. An interpretive chart of battle cries in arcade fighting games using the PAX scale.

\begin{tabular}{llll}
\hline Player-avatar sociality & PAX scale & Ludic elements & Battle cry features \\
\hline Emotional investment & Low & $\begin{array}{l}\text { Story is minimal, } \\
\text { not first-person based }\end{array}$ & Battle sounds are constant, emotive \\
\hline Anthropomorphic autonomy & High & $\begin{array}{l}\text { No avatar customization, } \\
\text { characters are established }\end{array}$ & Some randomization of battle sounds \\
\hline Suspension of disbelief & Low & Focus on fights not story & Violent sounds and phrases are hyper-real \\
\hline Sense of player control & High & $\begin{array}{l}\text { Active control of characters } \\
\text { and outcome }\end{array}$ & $\begin{array}{l}\text { Direct connection between controller action } \\
\text { and battle sound }\end{array}$ \\
\hline
\end{tabular}


of a male auteur than the female image can escape the male gaze (Silverman, 1988). What is more, the 'sound effect' of the female scream has its technological roots in pornography, and its cultural use as emotional climax in popular narratives makes it necessarily or at least potentially sexualized (Butkus, 2010). This makes the physically and interactionally demanding labor of playing an arcade fighting avatar already a gendered experience: this is why it matters that game women have gone from making very little sound to making a lot of sounds that primarily signal the sexuality, fragility, and audible effort of the virtual female body.

Given that battle cries are hyper-real in terms of vocal acting conventions, that is, they are exaggerated for both genders as well as for 'othered' characters such as monsters and hybrids, the gameplay experience of listening to female battle cries is one that engages the "reality principle" (Baudrillard, 1994) in particular ways. The 'reality principle,' introduced by Baudrillard, stipulates that hyper-reality in media functions in tandem with notions of 'reality,' whereby the othered hyper-reality of media constructs and reinforces the authentic reality of the outside-media world. In the case of battle cries, the exaggerated and sexualized female battle cries in arcade fighting games can be seen to function as distinct from 'what women really sound like' and thus further legitimize the aural objectification of stereotyped feminine aesthetics inside the gameplay experience. Presumably, for a heterosexual male player, there is both a satisfying recognition of female media tropes in the avatar vocalizations (e.g., the warrior, the witch, and the doll), and a subversive pleasure in enjoying them as direct auditory rewards for controller actions. For female players, hyper-real battle cries present the potential for conceiving of femininity as both 'other-than-myself' and as abject (Creed, 1993) when the power fantasy of playing a female avatar clashes with the reality of designer sonic stereotypes.

In this sense, the profound "distancing enacted by ventriloquism" (Nyerges, 2016, p. 116) that is part of the technological apparatus of battle cries, forces the player-male or female-to constantly slip between avatar identification states ranging from Avatar as Tool, Avatar as Symbiote, and Avatar as Other (Banks, 2015), thus disrupting the magic circle and synchronous flow states (Weber et al., 2009) of immersive gameplay. This slippage, I argue, is an enormously demanding affectation in terms of recognizing, resisting, enjoying, and rejecting sonic tropes as encoded performances of audible effort. Each of these avatar identification states elicit discreet affective reactions whereby virtual and actual worlds collide making virtual emotions real (Banks \& Bowman, 2016). These 'mediated emotions' are also co-constructive of real affective attitudes such as how male (and female) players would perceive femininity: as weaker, more frail, in terms of compulsory sexualization, and as a marker of victimhood and otherness. As a medium with a high intervention potential, games could be at the forefront of social change in terms of disrupting entrenched media tropes of gender, race, class, ability, etc.; yet so much of game design is focused on avoiding "expectancy violations" (Bowman, 2018, p. 17) when in actuality, stereotypical, hyper-real design elements such as gendered battle cries force players of any gender into the affective labor of weaving in and out of immersion due to disruptions in avatar identification and emotional investment.

\section{Conclusions}

Despite advancements in technology, or perhaps because of them the same design choices persist when it comes to gendered voicing in videogames, and to use a sonic metaphor, the tech actually amplifies the problem. Reliance on high-quality voice acting rather than short synthesized bursts brings with it the endemic representational problems of cinema, and even earlier theatrical and operatic typologies (Clément, 2000; Doane, 1985) all in the name of greater realism and immersion in the gaming experience. And that's where the heart of this problem lies: These massive titles represent what 'powerful' women should look and sound like. In some situations, these women are the mascots of the game; they are cosplayed at conventions and are featured in popular media, making their representational politics critically important. What is telling once we start looking at voice is the way sounding out the gendered body opens up different ways of exploring intentional and canonic designs of technological embodiment. This work is meant to revisit Doane's (1985) suggestion that media technologies and conventions come together to create the gendered 'fantasmic body,' which, by way of being mediated and technological within regimes of male gaze and ear (Silverman, 1988), reproduces politics of disempowerment in female game characters. At a higher level, Sterne's (2003) appeal to consider the mediated voice at the intersection of technology, history, and discourse, is animated here in the historical permutations of female battle cries, hopefully making a unique contribution to our understanding of how videogames intersect with and advance (or undermine) cultural norms about gender embodiment. Given the limitations of this case study, further work using both content analysis and a more systematic approach to spectrogram analysis is necessary to build knowledge and identify future trajectories for media production and game design. This research is unique in that it extends traditionally visual rubrics of media representation of gender to the sonic dimension, complicated by the particular interactivity and embodiment that characterize the relationships between player, avatar, and gameplay on screen. Through playful engagement with deconstructing and reconstructing the gendered nature of battle cries I hope to make the issues of media representation in gaming more accessible and engage both academics and the game community in broader conversations. 


\section{Acknowledgments}

The author wishes to acknowledge the seed funding that helped initialize this project from SSHRC partnership grant REFIG; as well as the work of Research Assistants at SFU Kaeleigh Evans, Nesan Fertado, and Renita Bangert.

\section{Conflict of Interests}

The author declares no conflict of interests.

\section{References}

Altman, R. (1980). Moving lips: Cinema as ventriloquism. Yale French Studies, 60, 67-79.

Banks, J. (2015). Object, me, symbiote, other: A social typology of player-avatar relationships. First Monday, 20(2). https://doi.org/10.5210/fm.v20i2.5433

Banks, J., \& Bowman, N. (2016). Emotion, anthropomorphism, realism, control: Validation of a merged metric for player-avatar interaction (PAX). Computers in Human Behavior, 54, 215-223.

Beard, M. (2014). The public voice of women. London Review of Books, 36(6), 11-14.

Behm-Morawitz, E., \& Mastro, D. (2009). The effects of the sexualization of female video game characters of gender stereotyping and female self-concept. Sex Roles, 61(11), 808-823.

Bizzocchi, J., \& Tanenbaum, T. (2011). Well read: Applying close reading techniques to gameplay experiences. In D. Davidson (Ed.), Well played 3.0 (pp. 218-315). Halifax: ETC Press.

Bonenfant, Y. (2014). On sound and pleasure: Mediations on the human voice. Sounding Out! Retrieved from https://soundstudiesblog.com/2014/06/30/onsound-and-pleasure-meditations-on-the-humanvoice

Baudrillard, J. (1994). Simulacra and simulation. Ann Arbor, MI: University of Michigan Press.

Bowman, N. (2018). Video games: A medium that demands our attention. New York, NY: Routledge.

Butkus, C. (2010). Depraved desire: Sadomasochism, sexuality and sound in mid-1970s cinema. In B. Johnson (Ed.), Earogenous zones: Sound, sexuality and cinema (pp. 66-88). Sheffield: Equinox Publishing.

Carson, A. (1995). The gender of sound. In A. Carson (Ed.), Glass, irony, and God (pp. 119-142). New York, NY: New Directions Books.

Cazden, J. (2017). Screaming for attention: The vocal demands of actors in violent interactive games. Journal of Voice, 31(1), 1-2.

Clément, C. (2000). Through voices, history. In M. A Smart (Ed.), Siren songs: Representations of gender and sexuality in opera (pp. 17-28). Princeton, NJ: Princeton University Press.

Corbett, J., \& Kapsalis, T. (1996). Aural sex: The female orgasm in popular sound. TDR, 40(3), 102-111.

Creed, B. (1993). The monstrous-feminine: Film, femi- nism, psychoanalysis. New York, NY: Routledge.

Doane, M. (1985). The voice in the cinema: The articulation of body and space. In E. Weis \& J. Belton (Eds.), Film sound: Theory and practice (pp. 162-176). New York, NY: Columbia University.

Droumeva, M. (2018). From Sirens to Cyborgs: The media politics of the female voice in games and game cultures. In K. Grey, G. Vorhees \& E. Vassen (Eds.), Feminism in Play (pp. 51-67). Palgrave Macmillan.

Droumeva, M., Evans, K., Fertado, N., \& Bangert, R. (2017). It gets worse...The female voice in videogames. First Person Scholar. Retrieved from http://www.firstpersonscholar.com/it-gets-worse/

Duran, M. (2018). Mortal Kombat characters from weakest to most powerful, officially ranked. The Gamer. Retrieved from https://www.thegamer.com/mortalkombat-characters-weakest-strong-ranked

Ehrick, C. (2015). Vocal gender and the gendered soundscape. Sounding Out! Retrieved from https:// soundstudiesblog.com/2015/02/02/vocal-genderand-the-gendered-soundscape-at-the-intersectionof-gender-studies-and-sound-studies

Ensslin, A. (2011). Recallin' Fagin: Linguistic accents, intertextuality and othering in narrative offline and online video games. In G. Crawford, V. K. Gosling, \& B. Light (Eds.), Online gaming in context: The social and cultural significance of online games. New York, NY: Routledge.

Evans, K. (2017). Soul Calibur: Research memo (Unpublished internal report).

James, R. (2016). Listening to sounds in postfeminist pop music. Sounding Out! Retrieved from https://soundstudiesblog.com/2016/02/15/ listening-to-sounds-in-post-feminist-pop-music

Kennedy, H. W. (2003). Game studies-Lara croft: Feminist icon or cyberbimbo? On the limits of textual analysis. Game Studies: The International Journal of Computer Game Research, 2(2). Retrieved from http://www.gamestudies.org/0202/kennedy

Lee, T. (2014). Street Fighter II's Chun-Li almost came with a shorter life bar. Ubergizmo. Retrieved from https://www.ubergizmo.com/2014/03/streetfighter-iis-chun-li-almost-came-with-a-shorter-lifebar

Loviglio, J. (2007). Sound effects: Gender, voice and the cultural work of NPR. The Radio JournalInternational Studies in Broadcast and Audio Media, 5(2/3), 67-81.

Nyerges, A. (2016). Hearing Hart Crane: In the shape of New York's noise. Sound Studies, 2(2), 107-118.

Reddit. (2015). Who do you think is the best voice actor in mkx? [Reddit thread]. Retrieved from https:// www.reddit.com/r/MortalKombat/comments/ 3knxoe/who_do_you_think_is_the_best_voice_ actor_in_mkx

Reddit. (2016). What do you think are the worst voices in SFV and should be taken out of the game? [Reddit thread]. Retrieved from https://www.reddit.com/ 
r/StreetFighter/comments/5as80i/what_do_you_ think_are_the_worst_voices_in_sfv_and

Ruberg, B. (2019). Video games have always been queer. New York, NY: NYU Press.

Silverman, K. (1988). The acoustic mirror: The female voice in psychoanalysis and cinema. Bloomington, IN: Indiana University Press.

Sterne, J. (2003). The audible past: Cultural origins of sound reproduction. Durham, NC: Duke University
Press.

Weber, R., Tamborini, R., Westcott-Baker, A., \& Kantor, B. (2009). Theorizing flow and media enjoyment as cognitive synchronization of attentional and reward networks. Communication Theory, 19(4), 397-422.

Zakharine, D. (Ed.). (2013). Electrified voices: Medial, socio-historical and cultural aspects of voice transfer. Göttingen: Vandenhoeck \& Ruprecht.

\section{About the Author}

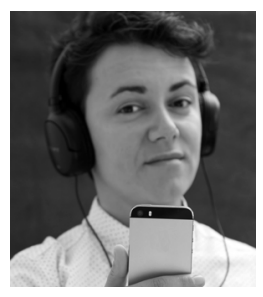

Milena Droumeva is an Assistant Professor of Communication and Glenfraser Professor of Sound Studies at Simon Fraser University, specializing in mobile technologies, sound studies, and multimodal ethnography. Milena has a background in acoustic ecology and works across the fields of urban soundscape research, sonification for public engagement, as well as gender and sound in video games. Milena's current research is focused on urban soundscapes and livability, and on critical approaches to sonification for social media. 